\title{
Chloroquine and hydroxychloroquine for the treatment of COVID-19: A living systematic review protocol
}

\author{
AUTHORS: \\ Rocío Bravo-Jeria \\ ORCID:0000-0002-3744-5578 \\ UC Evidence Center, Cochrane Chile Associated Center, Pontificia Universidad Católica de Chile, \\ Santiago, Chile \\ María Ximena Rojas Reyes \\ ORCID: 0000-0001-5752-7653 \\ Department of Research, Fundación Cardioinfantil, Bogotá, Colombia
}

\section{Juan Víctor Ariel Franco}

ORCID: 0000-0003-0411-899X

Department of Research, Instituto Universitario Hospital Italiano, Buenos Aires, Argentina

\section{María Paz Acuña}

ORCID: 0000-0001-7003-495X

Unidad de Infectología, Hospital Dr Sótero del Río, Santiago, Chile

Unidad de Infectología, Hospital Clínico Dra Eloísa Díaz, La Florida, Santiago, Chile

\section{Luz Ángela Torres López}

ORCID: 0000-0002-5130-4659

Department of Research, Fundación Cardioinfantil, Bogotá, Colombia

\section{Gabriel Rada}

ORCID iD: https://orcid.org/0000-0003-2435-0710

Fundación Epistemonikos, Santiago, Chile

UC Evidence Center, Cochrane Chile Associated Center, Pontificia Universidad Católica de Chile, Santiago, Chile

Internal Medicine Department, Faculty of Medicine, Pontificia Universidad Católica de Chile, Santiago, Chile

\section{COVID-19 L·OVE Working Group}

\section{Corresponding author:}

Gabriel Rada

Email address: radagabriel@epistemonikos.org

Postal address: Holanda 895, Providencia, Santiago, Chile. 
medRxiv preprint doi: https://doi.org/10.1101/2020.04.03.20052530; this version posted April 8, 2020. The copyright holder for this preprint (which was not certified by peer review) is the author/funder, who has granted medRxiv a license to display the preprint in perpetuity.

chloroquine and hydroxychloroquine for the treatment of

COVID-19: A living systematic review protocol

:OWG L:O

\section{ABSTRACT}

\section{Objective}

To determine the relative impact of the use of chloroquine and hydroxychloroquine on outcomes important to patients with COVID 19.

\section{Design}

This is the protocol of a living systematic review.

\section{Data sources}

We will conduct searches in PubMed/Medline, Embase, Cochrane Central Register of Controlled Trials (CENTRAL), trial registries, grey literature and in a centralised repository in L.OVE (Living OVerview of Evidence). L.OVE is a platform that maps PICO questions to evidence from Epistemonikos database. In response to the COVID-19 emergency, L.OVE was adapted to expand the range of evidence it covers and customised to group all COVID-19 evidence in one place. The search will cover the period until the day before submission to a journal.

\section{Eligibility criteria for selecting studies and methods}

We will follow a common protocol for multiple parallel systematic reviews, already published and submitted to PROSPERO (awaiting ID allocation).

We will include randomised controlled trials evaluating the effect of chloroquine and hydroxychloroquine - as monotherapy or in combination with other drugs - versus placebo or no treatment in patients with COVID-19. Randomised trials evaluating chloroquine and hydroxychloroquine in infections caused by other coronaviruses, such as MERS-CoV and SARS-CoV, and non-randomised studies in COVID-19 will be searched in case no direct evidence from randomised trials is found, or if the direct evidence provides low- or very low-certainty for critical outcomes.

Two reviewers will independently screen each study for eligibility, extract data, and assess the risk of bias. We will perform random-effects meta-analyses and use GRADE to assess the certainty of the evidence for each outcome.

A living, web-based version of this review will be openly available during the COVID-19 pandemic. We will resubmit it if the conclusions change or there are substantial updates.

\section{Ethics and dissemination}

No ethics approval is considered necessary. The results of this review will be widely disseminated via peer-reviewed publications, social networks and traditional media.

\section{Keywords}

COVID-19, severe acute respiratory syndrome coronavirus 2, Coronavirus Infections, Systematic review, Antimalarials, Hydroxychloroquine, Chloroquine. 
medRxiv preprint doi: https://doi.org/10.1101/2020.04.03.20052530; this version posted April 8, 2020. The copyright holder for this preprint (which was not certified by peer review) is the author/funder, who has granted medRxiv a license to display the preprint in perpetuity. It is made available under a CC-BY-NC-ND 4.0 International license .

Chloroquine and hydroxychloroquine for the treatment of

COVID-19: A living systematic review protocol

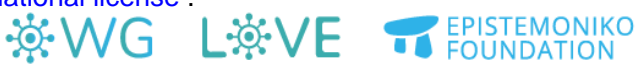

\section{INTRODUCTION}

COVID-19 is an infection caused by the SARS-CoV-2 coronavirus [1]. It was first identified in Wuhan, China, on December 31, 2019 [2]; three months later, almost half a million cases of contagion had been identified across 197 countries [3]. On March 11, 2020, WHO characterised the COVID-19 outbreak as a pandemic [1].

While the majority of cases result in mild symptoms, some might progress to pneumonia, acute respiratory distress syndrome and death [4],[5],[6]. The case fatality rate reported across countries, settings and age groups is highly variable, but it would range from about $0.5 \%$ to $10 \%$ [7]. In hospitalized patients it has been reported to be higher than $10 \%$ in some centres [8].

Many candidate drugs have been proposed as potentially effective, but the antimalarial agents chloroquine and hydroxychloroquine have attracted more attention than any other medication [9]. Some in vitro studies have suggested they would exert antiviral properties by inhibiting ph-dependant steps of viral replication [10], not only against SARS-COV-2, but also Chikungunya, Dengue, Zika, Influenza A H1N1 and H3N2, Coronavirus HCoV-229E, SARS-CoV and MERS-CoV, among others [11],[12]. Other researchers have found an anti-inflammatory and immune-stimulating effect mediated by TNF- $\alpha$ and IL- 6 that would block the cascade of events leading to acute respiratory distress syndrome [10].

Notwithstanding, despite its in vitro activity against several agents, to this date there is no acute viral infection that has been successfully treated by chloroquine or hydroxychloroquine. Moreover, in Chikungunya virus infection, chloroquine showed the paradoxical effect of leading to more chronic complications in the patients who received it, an outcome that would be explained by a delay in immune adaptive response [13]. The pathogenesis of COVID-19 is still unknown, therefore the clinical effects of administration of antimalarials in COVID-19 patients is largely unpredictable [14].

Theory aside, the use of antimalarials attracted attention after a news briefing by the Chinese government in February 2020 revealed that, according to several Chinese studies, chloroquine and hydroxychloroquine seemed 'to have apparent efficacy and acceptable safety against COVID-19' [15]. No empirical data supporting these findings have been published so far. A second boost of attention on antimalarials came after the release of a non-randomised study - with considerable methodological limitations - claiming that a combination of hydroxychloroquine and azithromycin achieved a high level of SARS-CoV-2 clearance in respiratory secretions [16 $]^{1}$.

Most researchers have asked for caution while we wait for the information from dozens of randomised trials already ongoing or planned, but the US Food and Drug Administration has authorized clinicians to prescribe it for patients admitted to hospital, despite warnings from scientific advisers [17] .

Using innovative and agile processes, taking advantage of technological tools, and resorting to the collective effort of several research groups, this living systematic review aims to provide a timely, 
medRxiv preprint doi: https://doi.org/10.1101/2020.04.03.20052530; this version posted April 8, 2020. The copyright holder for this preprint (which was not certified by peer review) is the author/funder, who has granted medRxiv a license to display the preprint in perpetuity.

Chloroquine and hydroxychloroquine for the treatment of

COVID-19: A living systematic review protocol

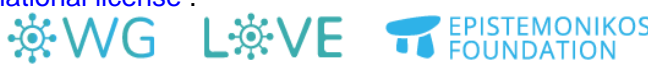

rigorous and continuously updated summary of the evidence available on the relative impact of the use of antimalarials on outcomes important to patients with COVID-19.

\section{METHODS}

\section{Protocol and registration}

This manuscript complies with the 'Preferred Reporting Items for Systematic reviews and Meta-Analyses' (PRISMA) guidelines for reporting systematic reviews and meta-analyses [18].

A protocol stating the shared objectives and methodology of multiple evidence syntheses (systematic reviews and overviews of systematic reviews) to be conducted in parallel for different questions relevant to COVID-19 was registered in PROSPERO (submitted, awaiting PROSPERO ID allocation) and published [19]. The protocol was adapted to the specificities of the question assessed in this review.

\section{Search strategies}

\section{Electronic searches}

Our literature search was devised by the team maintaining the L.OVE platform (https://app.iloveevidence.com), using the following approach:

1. Identification of terms relevant to the population and intervention components of the search strategy, using Word2vec technology [20] to the corpus of documents available in Epistemonikos Database.

2. Discussion of terms with content and methods experts to identify relevant, irrelevant and missing terms.

3. Creation of a sensitive boolean strategy encompassing all of the relevant terms

4. Iterative analysis of articles missed by the boolean strategy, and refinement of the strategy accordingly.

Our main search source was Epistemonikos database (https://www.epistemonikos.org), a comprehensive database of systematic reviews and other types of evidence [21]. We supplemented it with articles from multiple sources relevant to COVID-19 (without any study design, publication status or language restriction) [22].

In sum, Epistemonikos Database acts as a central repository. Only articles fulfilling Epistemonikos criteria are visible by users. The remaining articles are only accessible for members of COVID-19 L.OVE Working Group. 
medRxiv preprint doi: https://doi.org/10.1101/2020.04.03.20052530; this version posted April 8, 2020. The copyright holder for this preprint (which was not certified by peer review) is the author/funder, who has granted medRxiv a license to display the preprint in perpetuity.

chloroquine and hydroxychloroquine for the treatment of

COVID-19: A living systematic review protocol

:OWG L:O

Additional searches will be conducted using highly sensitive searches without any language or publication status restriction. The searches will cover from the inception date of each database until the day before submission:

Additional searches will be conducted using highly sensitive searches in PubMed/MEDLINE, the Cochrane Central Register of Controlled Trials (CENTRAL), Embase and the WHO International Clinical Trials Registry Platform, without any language or publication status restriction. The searches will cover from the inception date of each database until the day before submission.

The following strategy will be used to search in Epistemonikos Database. We will adapt it to the syntax of other databases.

(coronavir* OR coronovirus* OR "corona virus" OR "virus corona" OR "corono virus" OR "virus corono" OR hcov* OR "covid-19" OR covid19* OR "covid 19" OR "2019-nCoV" OR cv19* OR "cv-19" OR "cv 19" OR "n-cov" OR ncov* OR "sars-cov-2" OR (wuhan* AND (virus OR viruses OR viral)) OR (covid* AND (virus OR viruses OR viral)) OR "sars-cov" OR "sars cov" OR "sars-coronavirus" OR "severe acute respiratory syndrome" OR "mers-cov" OR "mers cov" OR "middle east respiratory syndrome" OR "middle-east respiratory syndrome") AND ((antimalari* OR "anti-malarial" OR "anti-malarials" OR "anti-malaria") OR (chloroquine* OR CQ OR Aralen) OR (hydroxychloroquine* OR HCQ OR Plaquenil))

\section{Other sources}

In order to identify articles that might have been missed in the electronic searches, we will do the following:

1. Screen the reference lists of other systematic reviews, and evaluate in full text all the articles they include.

2. Scan the reference lists of selected guidelines, narrative reviews and other documents.

3. Conduct cross-citation search in Google Scholar and Microsoft Academic, using each included study as the index reference.

4. Review websites from pharmaceutical companies producing drugs claimed as effective for COVID-19 drugs, websites or databases of major regulatory agencies, and other websites specialised in COVID-19.

5. Email the contact authors of all of the included studies to ask for additional publications or data on their studies, and for other studies in the topic.

6. Review the reference list of each included study. 
medRxiv preprint doi: https://doi.org/10.1101/2020.04.03.20052530; this version posted April 8, 2020. The copyright holder for this preprint (which was not certified by peer review) is the author/funder, who has granted medRxiv a license to display the preprint in perpetuity.

chloroquine and hydroxychloroquine for the treatment of

COVID-19: A living systematic review protocol

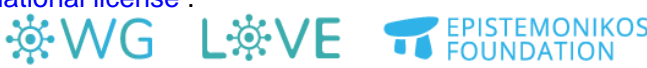

\section{Eligibility criteria}

\section{Types of studies}

We will preferently include randomised trials. However, information from non-randomised studies will be used if there is no direct evidence from randomised trials or the certainty of evidence for the critical outcomes resulting from the randomised trials is graded as low- or very low, and the certainty provided by the non-randomised evidence grades higher than the one provided by the randomised evidence [23].

We will exclude studies evaluating the effects on animal models or in vitro conditions.

\section{Types of participants}

We will include trials assessing participants with COVID-19, as defined by the authors of the trials. If substantial clinical heterogeneity on how the condition was defined is found, we will explore it using a sensitivity analysis.

In case no direct evidence from randomised trials is found, or if the evidence from randomised trials provides low- or very low-certainty evidence for critical outcomes, we will include information from randomised trials evaluating antimalarials in other coronavirus infections, such as MERS-CoV or SARS-CoV infections [23].

\section{Type of interventions}

The interventions of interest are the antimalarials chloroquine and hydroxychloroquine. We will not restrict our criteria to any dosage, duration, timing or route of administration.

The comparison of interest will be placebo (intervention plus optimal treatment versus placebo plus optimal treatment) or no treatment (antimalarials plus optimal treatment versus optimal treatment). Trials assessing antimalarials plus other drugs will be eligible if the cointerventions are identical in both intervention and comparison groups.

Trials evaluating antimalarials in combination with other active drugs versus placebo or no treatment will be also included.

\section{Type of outcomes}

We will not use the outcomes as an inclusion criteria during the selection process. Any article meeting all the criteria except for the outcome criterion will be preliminarily included and evaluated in full text. We used the core outcome set COS-COVID [24], the existing guidelines and reviews and the judgement of the authors of this review as an input to select the primary and secondary outcomes, as well as to decide upon inclusion. The review team will revise this list of outcomes, in order to incorporate ongoing efforts to define Core Outcomes Sets [25]. 
medRxiv preprint doi: https://doi.org/10.1101/2020.04.03.20052530; this version posted April 8, 2020. The copyright holder for this preprint (which was not certified by peer review) is the author/funder, who has granted medRxiv a license to display the preprint in perpetuity.

Chloroquine and hydroxychloroquine for the treatment of

COVID-19: A living systematic review protocol

Primary outcome

- All-cause mortality

Secondary outcomes

- Mechanical ventilation

- Extracorporeal membrane oxygenation

- Length of hospital stay

- Respiratory failure

- Serious adverse events

- Time to SARS-CoV-2 RT-PCR negativity

Other outcomes

- Acute respiratory distress syndrome

- Total adverse effects

Primary and secondary outcomes will be presented in the GRADE 'Summary of Findings' tables, and a table with all the outcomes will be presented as an appendix [26].

\section{Selection of studies}

The results of the literature search in Epistemonikos database will be automatically incorporated into the L.OVE platform (automated retrieval), where they will be de-duplicated by an algorithm comparing unique identifiers (database ID, DOI, trial registry ID), and citation details (i.e. author names, journal, year of publication, volume, number, pages, article title and article abstract).

The additional searches will be uploaded to the screening software Collaboratron ${ }^{\mathrm{TM}}[27]$.

In both L·OVE platform and Collaboratron ${ }^{\mathrm{TM}}$, two researchers will independently screen the titles and abstracts yielded by the search against the inclusion criteria. We will obtain the full reports for all titles that appear to meet the inclusion criteria or require further analysis to decide on their inclusion.

We will record the reasons for excluding trials in any stage of the search and outline the study selection process in a PRISMA flow diagram adapted for the purpose of this project.

\section{Extraction and management of data}

Using standardised forms, two reviewers will extract data independently from each included study. We will collect the following information: study design, setting, participant characteristics (including disease severity and age) and study eligibility criteria; details about the administered intervention and comparison, including dose and therapeutic scheme, duration, timing (i.e. time after diagnosis) and route of administration; the outcomes assessed and the time they were measured; the source of funding of the study and the conflicts of interest disclosed by the investigators; the risk of bias assessment for each individual study. 
medRxiv preprint doi: https://doi.org/10.1101/2020.04.03.20052530; this version posted April 8, 2020. The copyright holder for this preprint (which was not certified by peer review) is the author/funder, who has granted medRxiv a license to display the preprint in perpetuity.

Chloroquine and hydroxychloroquine for the treatment of

COVID-19: A living systematic review protocol

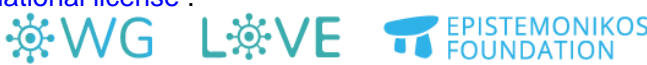

We will resolve disagreements by discussion, and one arbiter will adjudicate unresolved disagreements.

\section{Risk of bias assessment}

The risk of bias for each randomised trial will be assessed using a 'risk of bias' tool (RoB 2.0: a revised tool to assess risk of bias in randomised trials) [28]. We will consider the effect of assignment to the intervention for this review. Two reviewers will independently assess five domains of bias for each outcome result of all reported outcomes and time points. These five domains are: bias due to (1) the randomisation process, (2) deviations from intended interventions (effects of assignment to interventions at baseline), (3) missing outcome data, (4) measurement of the outcome, and (5) selection of reported results. Answers to signalling questions and supporting information collectively will lead to a domain-level judgement in the form of 'Low risk of bias', 'Some concerns', or 'High risk of bias'. These domain-level judgements will inform an overall 'risk of bias' judgement for each result. Discrepancies between review authors will be resolved by discussion to reach consensus. If necessary, a third review author will be consulted to achieve a decision.

We will assess their risks of bias with the Risk Of Bias In Non-randomised Studies of Interventions (ROBINS-I), a tool for assessing risk of bias in non-randomised studies of interventions [29]. We will assess the following domains: bias due to confounding, bias in selection of participants into the study, bias in classification of interventions, bias due to deviations from intended interventions (effect of assignment to intervention), bias due to missing data, bias in measurement of outcomes and bias in the selection of the reported result. We will judge each domain as low risk, moderate risk, serious risk, critical risk, or no information, and evaluate individual bias items as described in ROBINS-I guidance. We will not consider time-varying confounding, as these confounders are not relevant in this setting [29]. We will consider the following factors as baseline potential confounders:

- Age

- Comorbidity (e.g. cardiovascular disease, renal disease, eye disease, liver disease)

- Co-interventions

- Severity, as defined by the authors (i.e respiratory failure vs respiratory distress syndrome vs ICU requirement).

\section{Measures of treatment effect}

For dichotomous outcomes, we will express the estimate of treatment effect of an intervention as risk ratios (RR) or odds ratios (OR) along with 95\% confidence intervals (CI). For continuous outcomes, we will use mean difference and standard deviation (SD) to summarise the data using a $95 \% \mathrm{Cl}$. Whenever continuous outcomes are measured using different scales, the treatment effect will be expressed as a standardised mean difference $(\mathrm{SMD})$ with $95 \% \mathrm{Cl}$. When possible, we will multiply the SMD by a standard deviation that is representative from the pooled studies, for example, the SD from a well-known scale used by several of the studies included in the analysis on which the result is based. In cases where the minimally important difference (MID) is known, we will also present continuous 
medRxiv preprint doi: https://doi.org/10.1101/2020.04.03.20052530; this version posted April 8, 2020. The copyright holder for this preprint (which was not certified by peer review) is the author/funder, who has granted medRxiv a license to display the preprint in perpetuity.

Chloroquine and hydroxychloroquine for the treatment of

COVID-19: A living systematic review protocol .

outcomes as MID units or inform the results as the difference in the proportion of patients achieving a minimal important effect between intervention and control [30].

Then, these results will be displayed on the 'Summary of Findings Table' as mean difference [30].

\section{Strategy for data synthesis}

If we include more than one trial we will conduct meta-analysis for studies clinically homogeneous using RevMan 5 [31], using the inverse variance method with random effects model. For any outcomes where data was insufficient to calculate an effect estimate, a narrative synthesis will be presented.

\section{Subgroup and sensitivity analysis}

We will perform subgroup analysis according to the definition of severe COVID-19 infection (i.e respiratory failure vs respiratory distress syndrome vs ICU requirement). In case we identify significant differences between subgroups (test for interaction $<0.05$ ) we will report the results of individual subgroups separately.

We will perform sensitivity analysis excluding high risk of bias studies, and if non-randomised studies are used, excluding studies that did not report adjusted estimates. In cases where the primary analysis effect estimates and the sensitivity analysis effect estimates significantly differ we will either present the low risk of bias - adjusted sensitivity analysis estimates - or present the primary analysis estimates but downgrading the certainty of the evidence because of risk of bias.

\section{Assessment of certainty of evidence}

The certainty of the evidence for all outcomes will be judged using the Grading of Recommendations Assessment, Development and Evaluation working group methodology (GRADE Working Group) [32], across the domains of risk of bias, consistency, directness, precision and reporting bias. Certainty will be adjudicated as high, moderate, low or very low. For the main comparisons and outcomes, we will prepare Summary of Findings (SoF) tables [33],[34 and also interactive Summary of Findings (http://isof.epistemonikos.org/) tables. A SoF table with all the comparisons and outcomes will be presented as an appendix.

\section{Living evidence synthesis}

An artificial intelligence algorithm deployed in the Coronavirus/COVID-19 topic of the L·OVE platform (https://app.iloveevidence.com/loves/5e6fdb9669c00e4ac072701d) will provide instant notification of articles with a high likelihood to be eligible. The authors will review these and will decide upon inclusion, and will update the living web version of the review accordingly. We will consider resubmission to a journal if there is a change in the direction of the effect on the critical outcomes or a substantial modification to the certainty of the evidence.

This review is part of a larger project set up to produce multiple parallel systematic reviews relevant to COVID-19 [19]. 
medRxiv preprint doi: https://doi.org/10.1101/2020.04.03.20052530; this version posted April 8, 2020. The copyright holder for this preprint (which was not certified by peer review) is the author/funder, who has granted medRxiv a license to display the preprint in perpetuity.

Chloroquine and hydroxychloroquine for the treatment of

COVID-19: A living systematic review protocol

$\because: \%$ WG LOVE OT EPSTEMONIKOS

\section{NOTES}

\section{Acknowledgements}

The members of the COVID-19 L.OVE Working Group and Epistemonikos Foundation have made it possible to build the systems and compile the information needed by this project. Epistemonikos is a collaborative effort, based on the ongoing volunteer work of over a thousand contributors since 2012.

\section{Roles and contributions}

GR conceived the protocol. GR drafted the manuscript, and all other authors contributed to it. The corresponding author is the guarantor and declares that all authors meet authorship criteria and that no other authors meeting the criteria have been omitted.

The COVID-19 L.OVE Working Group was created by Epistemonikos and a number of expert teams in order to provide decision makers with the best evidence related to COVID-19. Up-to-date information about the group and its member organisations is available here: epistemonikos.cl/working-group

\section{Competing interests}

All authors declare no financial relationships with any organisation that might have a real or perceived interest in this work. There are no other relationships or activities that could have influenced the submitted work.

\section{Funding}

This project was not commissioned by any organisation and did not receive external funding. Epistemonikos Foundation is providing training, support and tools at no cost for all the members of the COVID-19 L·OVE Working Group.

\section{PROSPERO registration}

This protocol has been submitted (awaiting PROSPERO ID allocation).

\section{Ethics}

As researchers will not access information that could lead to the identification of an individual participant, obtaining ethical approval was waived.

\section{Data sharing}

All data related to the project will be available. Epistemonikos Foundation will grant access to data. 
medRxiv preprint doi: https://doi.org/10.1101/2020.04.03.20052530; this version posted April 8, 2020. The copyright holder for this preprint (which was not certified by peer review) is the author/funder, who has granted medRxiv a license to display the preprint in perpetuity. It is made available under a CC-BY-NC-ND 4.0 International license .

\section{REFERENCES}

1. World Health Organization. Director-General's remarks at the media briefing on 2019-nCoV on 11 February 2020. [Internet] World Health Organization; 2020 [Accessed April 3, 2020] Available from: https://www.who.int/dg/speeches/detail/who-director-general-s-remarks-at-the-media-briefi ng-on-2019-ncov-on-11-february-2020 .

2. Hui DS, I Azhar E, Madani TA, et al. The continuing 2019-nCoV epidemic threat of novel coronaviruses to global health - The latest 2019 novel coronavirus outbreak in Wuhan, China. Int J Infect Dis. 2020 Feb;91:264-266. Available from: doi: 10.1016/j.ijid.2020.01.009

3. Dong E, Du H, Gardner L. An interactive web-based dashboard to track COVID-19 in real time. Lancet Infect Dis. 2020 Feb 19 [Accessed April 3, 2020] Available from: https://doi.org/10.1016/S1473-3099(20)30120-1

4. Guan WJ, Ni ZY, Hu Y, et al. Clinical Characteristics of Coronavirus Disease 2019 in China. N Engl J Med 2020. Available from: doi:10.1056/NEJMoa2002032

5. Tavakoli, Ahmad, Vahdat, Katayon, Keshavarz, Mohsen. Novel Coronavirus Disease 2019 (COVID-19): An Emerging Infectious Disease in the 21st Century. BPUMS. 2020;22(6):432-450. Available from: doi:10.29252/ismj.22.6.432

6. Li LQ, Huang T, Wang YQ, Wang ZP, Liang Y, Huang TB, Zhang HY, Sun WM, Wang YP. 2019 novel coronavirus patients' clinical characteristics, discharge rate and fatality rate of meta-analysis. Journal of medical virology. 2020;. Available from: doi:10.1002/jmv.25757

7. Global Covid-19 Case Fatality Rates [Internet] UK: Centre for Evidence-Based Medicine (Accessed on April 3, 2020). Available from: https://www.cebm.net/covid-19/global-covid-19-case-fatality-rates/

8. Rodriguez-Morales AJ, Cardona-Ospina JA, Gutiérrez-Ocampo E, et al. Clinical, laboratory and imaging features of COVID-19: A systematic review and meta-analysis. Travel medicine and infectious disease. 2020;:101623. Available from: doi: 10.1016/j.tmaid.2020.101623

9. A malaria pill from the 1940s has caught the eyes of doctors, analysts, and even Elon Musk as a potential coronavirus treatment. [Internet]. Business insider. Available from: https://www.businessinsider.com/malaria-pill-chloroquine-tested-as-coronavirus-treatment-2020-3

10. Savarino A, Boelaert JR, Cassone A, Majori G, Cauda R. Effects of chloroquine on viral infections: an old drug against today's diseases? Lancet Infect Dis 2003;3:722-7.

11. D'Alessandro S, Scaccabarozzi D, Signorini L, Perego F, Ilboudo DP, Ferrante P, Delbue S. The Use of Antimalarial Drugs against Viral Infection. Microorganisms. 2020 Jan 8;8(1). pii: E85. doi: 10.3390/microorganisms8010085

12. Devaux CA, Rolain JM, Colson P, Raoult D. New insights on the antiviral effects of chloroquine against coronavirus: what to expect for COVID-19?. International journal of antimicrobial agents. 2020;:105938. 
medRxiv preprint doi: https://doi.org/10.1101/2020.04.03.20052530; this version posted April 8, 2020. The copyright holder for this preprint (which was not certified by peer review) is the author/funder, who has granted medRxiv a license to display the preprint in perpetuity. It is made available under a CC-BY-NC-ND 4.0 International license .

Chloroquine and hydroxychloroquine for the treatment of

COVID-19: A living systematic review protocol

:

13. Roques P, Thiberville S.D, Dupuis -Maguiraga L, et al. Paradoxical Effect of Chloroquine Treatment in Enhancing Chikungunya Virus Infection. Viruses 2018; 10,268: 1 -18.

14. Guastalegname M, Vallone A. Could chloroquine/hydroxychloroquine be harmful in Coronavirus Disease 2019 (COVID-19) treatment?. Clinical infectious diseases : an official publication of the Infectious Diseases Society of America. 2020;

15. Gao J, Tian Z, Yang X. Breakthrough: Chloroquine phosphate has shown apparent efficacy in treatment of COVID-19 associated pneumonia in clinical studies. Biosci Trends. [Internet] 2020 Mar 16 [Accessed March 26] 14(1):72-73. Available from: doi: https://doi.org/10.5582/bst.2020.01047

16. Gautret et al. Hydroxychloroquine and azithromycin as a treatment of COVID-19: results of an open-label non-randomized clinical trial. International Journal of Antimicrobial Agents - In Press 17 March 2020 - DOI : 10.1016/j.ijantimicag.2020.105949

17. Lenzer J. Covid-19: US gives emergency approval to hydroxychloroquine despite lack of evidence. BMJ. 2020 Apr 1;369:m1335. doi: 10.1136/bmj.m1335

18. Moher D, Shamseer L, Clarke M, et al. Preferred reporting items for systematic review and meta-analysis protocols (PRISMA-P) 2015 statement. Syst Rev. [Internet] 2015 Jan 1 [Accessed March 26] ;4:1. Available from: doi: 10.1186/2046-4053-4-1

19. Rada G, Verdugo-Paiva F, Ávila C, Morel-Marambio M, Bravo-Jeria R, Pesce F, Madrid E, Izcovich A; COVID-19 L.OVE Working Group. Evidence synthesis relevant to COVID-19: a protocol for multiple systematic reviews and overviews of systematic reviews. Medwave 2020;20(3):e7867 doi: 10.5867/medwave.2020.03.7867

20. Github repository [Internet] (Accessed on April 3, 2020) Available from: https://github.com/dperezrada/keywords2vec

21. Epistemonikos Database Methods [Internet] Santiago: Epistemonikos Foundation (Accessed on April 3, 2020) Available from: https://www.epistemonikos.org/en/about us/methods

22. Methods for the special L.OVE of Coronavirus infection [Internet] Santiago: Epistemonikos Foundation (Accessed on April 3, 2020) Available from: https://app.iloveevidence.com/covid-19

23. Schünemann HJ, Cuello C, Akl EA, Mustafa RA, Meerpohl JJ, Thayer K, Morgan RL, Gartlehner G, Kunz R, Katikireddi SV, Sterne J, Higgins JP, Guyatt G; GRADE Working Group. GRADE guidelines: 18. How ROBINS-I and other tools to assess risk of bias in nonrandomized studies should be used to rate the certainty of a body of evidence. J Clin Epidemiol. 2019 Jul;111:105-114. doi: 10.1016/j.jclinepi.2018.01.012

24. Xinyao Jin, Bo Pang, Junhua Zhang, et al. Core Outcome Set for Clinical Trials on Coronavirus Disease 2019 (COS-COVID), Engineering, 2020. https://doi.org/10.1016/j.eng.2020.03.002.

25. COVID-19 Core Outcomes [Internet]. Accessed on April 3, 2020) Available from: https://www.covid-19-cos.org/

26. Guyatt GH, Oxman AD, Santesso N, et al. GRADE guidelines: 12. Preparing summary of findings tables-binary outcomes. J Clin Epidemiol [Internet] 2013 Feb [Accessed March 26] ;66(2):158-72. Available from: doi: 10.1016/j.jclinepi.2012.01.012

27. Website [Internet]. Available from: Epistemonikos Foundation. Collaboratron [Software]: https://collaboratron.epistelab.com (accessed April 3, 2020) 
medRxiv preprint doi: https://doi.org/10.1101/2020.04.03.20052530; this version posted April 8, 2020. The copyright holder for this preprint (which was not certified by peer review) is the author/funder, who has granted medRxiv a license to display the preprint in perpetuity.

Chloroquine and hydroxychloroquine for the treatment of

COVID-19: A living systematic review protocol

28. Sterne JAC, Savović J, Page MJ, Elbers RG, Blencowe NS, Boutron I, Cates CJ, Cheng HY, Corbett MS, Eldridge SM, Emberson JR, Hernán MA, Hopewell S, Hróbjartsson A, Junqueira DR, Jüni $P$,

Kirkham JJ, Lasserson T, Li T, McAleenan A, Reeves BC, Shepperd S, Shrier I, Stewart LA, Tilling $\mathrm{K}$, White IR, Whiting PF, Higgins JPT. RoB 2: a revised tool for assessing risk of bias in randomised trials. BMJ. 2019 Aug 28;366:14898. doi: 10.1136/bmj.l4898

29. Sterne JA, Hernán MA, Reeves BC, Savović J, Berkman ND, Viswanathan M, Henry D, Altman DG, Ansari MT, Boutron I, Carpenter JR, Chan AW, Churchill R, Deeks JJ, Hróbjartsson A, Kirkham J, Jüni P, Loke YK, Pigott TD, Ramsay CR, Regidor D, Rothstein HR, Sandhu L, Santaguida PL, Schünemann HJ, Shea B, Shrier I, Tugwell P, Turner L, Valentine JC, Waddington $\mathrm{H}$, Waters $\mathrm{E}$, Wells GA, Whiting PF, Higgins JP. ROBINS-I: a tool for assessing risk of bias in non-randomised studies of interventions. BMJ. 2016 Oct 12;355:i4919. doi: 10.1136/bmj.i4919

30. Guyatt GH, Oxman AD, Santesso N, et al. GRADE guidelines: 12 . Preparing summary of findings tables-binary outcomes. J Clin Epidemiol [Internet] 2013 Feb [Accessed March 26] ;66(2):158-72. Available from: doi: 10.1016/j.jclinepi.2012.01.012

31. Review Manager (RevMan) [Computer program]. Version 5.3.5 Copenhagen: The Nordic Cochrane Centre, The Cochrane Collaboration, 2014]

32. Guyatt GH, Oxman AD, Vist GE, Kunz R, Falck-Ytter Y, Alonso-Coello P, Schünemann HJ; GRADE Working Group. GRADE: an emerging consensus on rating quality of evidence and strength of recommendations. BMJ. 2008 Apr 26;336(7650):924-6. doi: 10.1136/bmj.39489.470347.AD

33. Guyatt GH, Oxman AD, Santesso N, Helfand M, Vist G, Kunz R, Brozek J, Norris S, Meerpohl J, Djulbegovic B, Alonso-Coello P, Post PN, Busse JW, Glasziou P, Christensen R, Schünemann HJ. GRADE guidelines: 12. Preparing summary of findings tables-binary outcomes. J Clin Epidemiol. $2013 \quad$ Feb;66(2):158-72. doi: 10.1016/j.jclinepi.2012.01.012pubmed/22609141?report=docsum\&format=text

34. Guyatt GH, Thorlund K, Oxman AD, et al. GRADE guidelines: 13. Preparing summary of findings tables and evidence profiles-continuous outcomes. J Clin Epidemiol [Internet] 2013 Feb [Accessed March 26] ;66(2):173-83. Available from: doi: 10.1016/j.jclinepi.2012.08.001 